OPEN ACCESS

Edited by:

Bey Hing Goh,

Monash University Malaysia Campus,

Malaysia

Reviewed by:

Pinarosa Avato,

University of Bari Aldo Moro, Italy Benedict Green,

Poisonous Plant Research Laboratory

(ARS-USDA), USA

${ }^{*}$ Correspondence:

Yanhua Li

liyanhua1970@163.com

tThese authors have contributed equally to this study and share first

authorship.

Specialty section:

This article was submitted to

Ethnopharmacology,

a section of the journal

Frontiers in Pharmacology

Received: 04 November 2016

Accepted: 16 January 2017

Published: 30 January 2017

Citation:

Bai J, Yang Y, Wang S, Gao L,

Chen J, Ren Y, Ding W,

Muhammad I and Li Y (2017) Syringa oblata Lindl. Aqueous Extract Is a Potential Biofilm Inhibitor in S. suis.

Front. Pharmacol. 8:26.

doi: 10.3389/fphar.2017.00026

\section{Syringa oblata Lindl. Aqueous Extract Is a Potential Biofilm Inhibitor in S. suis}

\author{
Jingwen Bait, Yanbei Yangt, Shuai Wang, Lingfei Gao, Jianqing Chen, Yongzhi Ren, \\ Wenya Ding, Ishfaq Muhammad and Yanhua Li*
}

College of Veterinary Medicine, Northeast Agricultural University, Harbin, China

Streptococcus suis (S. suis) is a zoonotic pathogen that causes severe disease symptoms in pigs and humans. Syringa oblata Lindl. distributed in the middle latitudes of Eurasia and North America were proved as the most development potential of Chinese Medicine. In this study, biofilm formation by $S$. suis decreased after growth with 1/2 MIC, 1/4 MIC, or 1/8 MIC of Syringa oblata Lindl. aqueous extract and rutin. Scanning electron microscopy analysis revealed the potential effect of Syringa oblata Lindl. aqueous extract and rutin against biofilm formation by S. suis. Using iTRAQ technology, comparative proteomic analyses was performed at two conditions: 1/2 MIC of Syringa oblata Lindl. aqueous extract treated and non-treated cells. The results revealed the existence of 28 proteins of varying amounts. We found that the majority of the proteins were related to cell growth and metabolism. We also found that Syringa oblata Lindl. Aqueous extract affected the synthesis enzymes. In summary, Syringa oblata Lindl. aqueous extract might be used to inhibit the biofilm formation effectively by $S$. suis, and the active ingredients of the Syringa oblate Lindl. aqueous extract is rutin. The content of rutin is $9.9 \pm 0.089 \mathrm{mg} / \mathrm{g}$ dry weight.

Keywords: proteomics, Streptococcus suis, Syringa oblata Lindl., biofilm formation

\section{INTRODUCTION}

Streptococcus suis (S. suis) is a major bacterial pathogen of young pigs and a worldwide economic problem for the pig industry (Goyette-Desjardins et al., 2014). Furthermore, S. suis is emerging as a zoonotic pathogen associated with meningitis and septicaemia in humans (Ferrando et al., 2014). In one often-cited statistic sourced from the US National Institutes of Health (NIH), biofilms are indicated as the cause of $>60 \%$ of all clinical microbial infections (Abbanat et al., 2014). Moreover, some studies have demonstrated that $S$. suis has the ability to form biofilms (Brown et al., 1988; Brady et al., 2008). Biofilms are defined as consortia of microorganisms that are attached to a biotic or abiotic surface. In addition, microorganisms embedded in the biofilm offers more resistant to desiccation, environmental stress (nutritional or oxidative stress), and UV lightexposure (Lee et al., 2008; Rao et al., 2008).

The S. suis serotypes are determined by the antigenicity of capsule. To date, S. suis have 33 serotypes according to antigenic differences in the capsular polysaccharide (CPS) (Wang et al., 2011). The cps genes code for the production of capsule (Smith et al., 1999). S. suis serotyping based on variation in the capsule structures encoded by cps locus genes accountable for capsule formation (Liu et al., 2013). 
Now days, the majority of drugs produced from naturally occurring molecules, especially the anti-infective agents. Newman and Cragg surveyed that natural products, or drugs obtained from natural product scaffolds, account for $>75 \%$ of the 97 accepted antibacterial New Chemical Entities intercalate over the period 1981-2006, shows the significance of natural products used in clinics against infectious diseases (Taylor, 2013). The discovery of new drugs for curing various diseases mostly comes from biologically active natural products, especially the plant-derived ones (Coleman et al., 2010; Koh et al., 2013). Particularly, some plants grow in an environment that has high bacterial density and so they have co-existed with bacteria during their evolution. Accordingly, the plants may have evolved protective mechanisms against bacterial infections, and may even produce bacterial biofilm inhibitors (Zhu et al., 1998; Ding et al., 2011). Folium syringae leaves are mainly from the dry leaves of Oleaceae plant: Syringa oblate Lindl., Syringa diatata Nakai and Syringa vulgaris L., which were proved as the most development potential of Chinese Medicine through its plant resources, chemical constituents, pharmacological action and clinical application. Syringa has been widely cultivated in the northern parts of China and Korea. The traditional Chinese treatment uses the leaf, flowerbud, and bark of Syringa to treat various infections, heal inflammations, dampness and acute icteric hepatitis (Feng et al., 2009). In Korea, the stem bark of Syringa has been used for the treatment of tooth pain, intestinal disorders and diarrhea (Park et al., 1999).

We have analyzed the relationship between the spectrum and the impact of Syringa oblata Lindl. aqueous extract on S. suis biofilms in vitro. According to HPLC fingerprint and anti-biofilm activity test, gray relational analysis was applied to find the active compositions. According to the relational grade, rutin make significant contribution to anti-biofilm activity. Rutin is a well-known and widely used citrus flavonoid glycoside between flavonol quercetin and disaccharide rutinose. It is found in many foods, such as buckwheat, onion, lemon, apple, orange, and grapefruit. Rutin has a lot of benefit pharmacological effects, such as anti-inflammatory, antimicrobial, antioxidant, and antihypertensive effects (Erlund et al., 2000; Middleton et al., 2000).

Our laboratory recently reported that sub-MICs of emodin and sub-MICs of erythromycin inhibited biofilm formation by S. suis ATCC 700794 (Yang et al., 2015; Zhao et al., 2015). However, the relationship between Syringa oblata Lindl. and biofilm formation by $S$. suis remains poorly understood. The objective of this study was to search new potential inhibitors for the control of biofilm formation by S. suis; and to describe the use of proteomics to better understand the impact of Syringa oblata Lindl. aqueous extract on S. suis biofilms in vitro.

\section{MATERIALS AND METHODS}

\section{Preparation of Syringa oblata Lindl. Aqueous Extract}

Syringa oblata Lindl. was collected in Northeast Agricultural University (Harbin, Heilongjiang, China). Taxonomic identi- fication was confirmed by Professor Xiuju Wu (Heilongjiang University of traditional Chinese Medicine, Harbin, China). A coarsely powdered, air-dried, Syringa oblata Lindl. (leaves, $200 \mathrm{~g}$ ) was boiled in $2 \mathrm{~L}$ of distilled water for $45 \mathrm{~min}$, decanted and filtered. The filtrate was evaporated to dryness in an oven set at $60^{\circ} \mathrm{C}$. The dried Syringa oblata Lindl. extract was weighed and reconstituted to a concentration of $100 \mathrm{mg} / \mathrm{mL}$.

\section{HPLC and HPLC-ESI-MS Analysis of Syringa oblata Lindl. Aqueous Extract}

On-line HPLC measurements were performed on Waters Alliance HPLC system (Shimadzu Corporation, Kyoto, Japan) consisting of a binary pump and a UV/V is detector. The separation was achieved using a DL-Cl8 column (4.6 $\mathrm{mm} \times 250 \mathrm{~mm}, 5 \mu \mathrm{m}$, Japan) at $25^{\circ} \mathrm{C}$. The mobile phase was composed of acetonitrile (A) and $0.1 \%$ formic acid (B). The rate of flow was $1.0 \mathrm{~mL} / \mathrm{min}$. The volume injected was $20 \mu \mathrm{L}$ and the detection wavelength was $245 \mathrm{~nm}$.

For LC-MS analysis, the Agilent 3000 HPLC system was coupled on-line to an LC/MSD Trap SL Plus spectrometer (Agilent, Corp., Massachusetts, American) equipped with electrospray ionization (ESI) source. In order to ionize the target compound, ESI in both positive- and negative-ion modes was investigated. The MS was operated in MRM mode, and the capillary voltage and the ion spray voltage were set at 3.0 and $5.5 \mathrm{kV}$, respectively. Ultrahigh-purity helium was used as the collision gas (10 p.s.i.) and high-purity nitrogen as the nebulizing gas (12 p.s.i.). The source temperature was set at $300^{\circ} \mathrm{C}$. For full scan MS analysis, the spectra were recorded in the range $\mathrm{m} / \mathrm{z}$ $100-1000$.

\section{Identification and Quantification of Rutin}

Rutin in the Syringa oblata Lindl. aqueous extract was identified by comparing its mass spectrum with literature data (Regos et al., 2009; Zhao et al., 2013), and comparing the HPLC retention time with that of the authentic standard. Quantification of rutin in the aqueous extract was carried out based on linear calibration plot of the peak area in HPLC at $245 \mathrm{~nm}$ against concentration using the external standard method.

\section{Experimental Bacterial Strain and Culture Conditions}

Streptococcus suis ATCC 700794 was used in this study. Bacteria were cultured at $37^{\circ} \mathrm{C}$ in Todd-Hewitt broth (THB; Summus, Ltd, Harbin, Heilongjiang, China) or Todd-Hewitt broth agar (THA) added with $5 \%(\mathrm{v} / \mathrm{v})$ fetal bovine serum (Sijiqing, Ltd, Hangzhou, Zhejiang, China). In order to obtain THA, The original THB was added with 1.8\% Bacto-agar (Difco Laboratories). The media were sterilized in autoclave (30 min at $115^{\circ} \mathrm{C}$ ) and before inoculation, all strains were transferred from the stock cultures to THA and incubated aerobically at $37^{\circ} \mathrm{C}$ for $16 \mathrm{~h}$. Then, all strains were sub-cultured one more time under the same conditions. The cultures were used for the minimal inhibitory concentration (MIC) assays and the biofilm assays. 


\section{Determination of MIC}

Minimal inhibitory concentration of Syringa oblata Lindl. aqueous extract and rutin (dissolved in Methanol) (Guoyao, Ltd, China) was determined three times using the protocol described by Wiegand et al. (2008), with a few modifications. Briefly, The sterile saline solutions were used for the dilution of overnight cultures of $S$. suis to obtain the turbidity of a so-called McFarland 0.5 standard (corresponding to $1 \times 10^{8}$ colony-forming units [CFUs]/mL). Then, $5 \%(\mathrm{v} / \mathrm{v})$ fetal bovine serum was added to sterile THB to dilute the cultures of $S$. suis (1:100). $100 \mu \mathrm{L}$ of each sample was added to the wells of a Costar ${ }^{\circledR} 3599$ 96-well plate (Corning, NY, USA) containing serial dilutions of Syringa oblata Lindl. aqueous extract and rutin in culture medium $(100 \mu \mathrm{L})$. Bacteria grown as control were cultured in the absence of Syringa oblata Lindl. aqueous extract and rutin. After incubation for $24 \mathrm{~h}$ at $37^{\circ} \mathrm{C}$, the MIC was determined as the lowest concentration of Syringa oblata Lindl. aqueous extract and rutin that completely inhibited S. suis growth.

\section{Biofilm Assay}

Streptococcus suis strain was cultured overnight and diluted to an optical density of 0.1 at $660 \mathrm{~nm}$ (OD 660). Same amount of $S$. suis was grown in a $\operatorname{Costar}^{\circledR} 3599$ 96-well plate in the presence of 1/2 MIC, 1/4 MIC, 1/8 MIC, or 1/16 MIC of Syringa oblata Lindl. aqueous extract and rutin. S. suis ATCC 700794 treated without Syringa oblata Lindl. aqueous extract and rutin was served as a control. Biofilms were treated as described by Yang et al. (2015) with some modifications. Briefly, the medium, free-floating bacteria, and loosely bound biofilm were removed by aspiration, and the wells were washed thrice with sterile physiological saline. The remaining bacteria were fixed with $200 \mu \mathrm{L}$ methanol (99\%) (Guoyao, Ltd, China) per well, and after $15 \mathrm{~min}$, plates were dried and emptied. Then, plates were stained for $5 \mathrm{~min}$ with $200 \mu \mathrm{L}$ crystal violet (2\%) (Guoyao, Ltd, China) per well. The excess stain was washed with water. Then the dye was resolubilized with $200 \mu \mathrm{L}$ glacial acetic acid (33\%) (Guoyao, Ltd, China) per well. A microplate reader (DG5033A, Huadong, Ltd, Nanjing, Jiangsu, China) was used to quantify the amount of released stain at absorbance of $570 \mathrm{~nm}$.

\section{Scanning Electron Microscopy (SEM)}

Scanning electron microscope (SEM) was used to examine the S. suis biofilm (refer to Bedran et al., 2014). Briefly, $1 \mathrm{~mL}$ of S. suis were diluted to an optical density of 0.1 at $600 \mathrm{~nm}\left(\mathrm{OD}_{600}\right)$ in culture without Syringa oblata Lindl. aqueous extract or with 1/2 MIC of Syringa oblata Lindl. aqueous extract was added into wells of a 6-well plate containing glass slide. The same condition was treated for rutin. After $24 \mathrm{~h}$ incubation, medium and free-floating bacteria were removed. The biofilms were incubated overnight in fixation buffer $(4 \%(\mathrm{w} / \mathrm{v})$ paraformaldehyde, $2.5 \%(\mathrm{w} / \mathrm{v})$ glutaraldehyde, $2 \mathrm{mM} \mathrm{CaCl}_{2}$ in $0.2 \mathrm{M}$ cacodylate buffer, $\mathrm{pH} 7.2$ ), washed with $0.1 \mathrm{M}$ cacodylate buffer $\mathrm{pH} 7.0(3 \mathrm{~min} \times 20 \mathrm{~min})$ and post-fixed for $90 \mathrm{~min}$ at room temperature in $1 \%(\mathrm{w} / \mathrm{v})$ osmic acid containing $2 \mathrm{mM}$ potassium ferrocyanide and $6 \%$ $(\mathrm{w} / \mathrm{v})$ sucrose in cacodylate buffer. The samples were dried, gold sputtered with an ion sputtering instrument (current $15 \mathrm{~mA}, 2 \mathrm{~min}$ ) and finally observed using SEM (FEI Quanta, Netherlands).

\section{Protein Digestion and iTRAQ Labeling}

Protein was extracted from $S$. suis cells at two different conditions (1/2 MIC of Syringa oblata Lindl. aqueous extract treated cells and non-treated cells). iTRAQ analysis was implemented at Shanghai Applied Protein Technology, Co. Ltd (APT, Shanghai, China). Three biological replicates were evaluated to minimize the influence of less reliable quantitative information.

Protein digestion was carried out according to the reported FASP procedure (Wisniewski et al., 2009). Briefly, $200 \mu \mathrm{g}$ of proteins for each sample were incorporated into $30 \mu \mathrm{L}$ STD buffer (4\% SDS, $100 \mathrm{mM}$ DTT, $150 \mathrm{mM}$ Tris- $\mathrm{HCl} \mathrm{pH} \mathrm{8.0).} \mathrm{The}$ detergent, DTT and other low-molecular-weight components were removed using UA buffer ( $8 \mathrm{M}$ Urea, $150 \mathrm{mM}$ Tris- $\mathrm{HCl}$ $\mathrm{pH}$ 8.0) by repeated ultrafiltration (Microcon units, $30 \mathrm{kD}$ ). Then $100 \mu \mathrm{L} 0.05 \mathrm{M}$ iodoacetamide in UA buffer was added to block reduced cysteine residues and the samples were incubated for $20 \mathrm{~min}$ in the dark. The filters were washed three times with $100 \mu \mathrm{L}$ UA buffer and two times with $100 \mu \mathrm{L}$ DS buffer (50 mM triethylammoniumbicarbonate at $\mathrm{pH} 8.5$ ) respectively. Then, the protein suspensions were digested with $2 \mu \mathrm{g}$ trypsin (Promega) in $40 \mu \mathrm{L}$ DS buffer overnight at $37^{\circ} \mathrm{C}$, and the filtrate (peptides) were collected. The peptide content was quantified by UV light spectral density at $280 \mathrm{~nm}$ using an extinctions coefficient of 1.1 of $0.1 \%(\mathrm{~g} / \mathrm{l})$ solution that was calculated on the basis of the frequency of tryptophan and tyrosine in vertebrate proteins.

For the iTRAQ labeling, the peptides were labeled with the 8plex iTRAQ reagent by following the manufacturer's instructions (Applied Biosystems). Each iTRAQ reagent was dissolved in $70 \mu \mathrm{L}$ of ethanol and added to the respective peptide mixture. The peptides from the S. suis biofilms treated by Syringa oblata Lindl. aqueous extract were labeled with 115 isobaric reagent, and the peptides from the non-treated $S$. suis biofilms were labeled with 116 isobaric reagent. Then, the samples were multiplexed and vacuum dried. Three independent biological experiments were performed.

\section{Peptide Fractionation with Strong Cation Exchange (SCX) Chromatography}

Strong cation exchange (SCX) chromatography AKTA Purifier system (GE Healthcare) was used for iTRAQ labeled peptides fractionation. The dried peptide mixture was reconstituted and acidified with $2 \mathrm{~mL}$ buffer $\mathrm{A}\left(10 \mathrm{mM} \mathrm{KH}_{2} \mathrm{PO}_{4}\right.$ in $25 \%$ of $\mathrm{ACN}, \mathrm{pH} 2.7$ ) and loaded onto a PolySULFOETHYL $4.6 \mathrm{~mm} \times 100 \mathrm{~mm}$ column $(5 \mu \mathrm{m}, 200 \AA$, PolyLC, Inc., Columbia, MD, USA). The peptides were eluted at a flow rate of $1 \mathrm{ml} / \mathrm{min}$ with a gradient of $0-10 \%$ buffer $\mathrm{B}(500 \mathrm{mM} \mathrm{KCl}$, $10 \mathrm{mM} \mathrm{KH}_{2} \mathrm{PO}_{4}$ in $25 \%$ of $\mathrm{ACN}, \mathrm{pH} 2.7$ ) for $2 \mathrm{~min}, 10-20 \%$ buffer B for $25 \mathrm{~min}, 20-45 \%$ buffer B for $5 \mathrm{~min}$, and 50 $100 \%$ buffer B for $5 \mathrm{~min}$. The separation was monitored by absorbance at $214 \mathrm{~nm}$, and the fractions were collected after 
every $1 \mathrm{~min}$. The obtained fractions (approximately 30 fractions) were combined into 10 pools and desalted on C18 Cartridges [Empore $^{\mathrm{TM}}$ SPE Cartridges C18 (standard density), bed I.D. $7 \mathrm{~mm}$, volume $3 \mathrm{ml}$, Sigma]. All fractions were concentrated by vacuum centrifugation and reconstituted in $40 \mu \mathrm{L}$ of $0.1 \%(\mathrm{v} / \mathrm{v})$ trifluoroacetic acid. And samples were stored at $-80^{\circ} \mathrm{C}$ until LC-MS/MS analysis.

\section{Liquid Chromatography (LC) - Electrospray lonization (ESI) Tandem MS (MS/MS) Analysis by Q Exactive}

$\mathrm{Q}$ Exactive mass spectrometer was used for experiments that were coupled to Easy nLC (Proxeon Biosystems, now Thermo Fisher Scientific). Each fraction $(10 \mu \mathrm{L})$ was injected for the nanoLCMS/MS analysis. The peptide mixture $(5 \mu \mathrm{g})$ was loaded onto a C18-reversed phase column (Thermo Scientific Easy Column, $10 \mathrm{~cm}$ long, $75 \mu \mathrm{m}$ inner diameter, $3 \mu \mathrm{m}$ resin) in buffer $\mathrm{A}(0.1 \%$ formic acid) and separated with a linear gradient of buffer $\mathrm{B}(80 \%$ acetonitrile and $0.1 \%$ formic acid) at a flow rate of $250 \mathrm{nl} / \mathrm{min}$ controlled by IntelliFlow technology over $140 \mathrm{~min}$. MS data were acquired using a data-dependent top 10 method dynamically choosing the most abundant precursor ions from the survey scan $(300-1800 \mathrm{~m} / \mathrm{z})$ for HCD fragmentation. Determination of the target value is based on predictive Automatic Gain Control (pAGC). Dynamic exclusion duration was $60 \mathrm{~s}$. Survey scans were acquired at a resolution of 70,000 at $\mathrm{m} / \mathrm{z} 200$, and resolution for HCD spectra was fixed at 17,500 at $\mathrm{m} / \mathrm{z} 200.30 \mathrm{eV}$ was normalized collision energy and the underfill ratio, which shows the minimum percentage of the target value likely to be reached at maximum fill time, was defined as $0.1 \%$. The experiment run with the peptide recognition mode enabled.

\section{Sequence Database Searching and Data Analysis}

The MS/MS spectra were searched using the MASCOT engine (Matrix Science, London, UK; version 2.2) in the Proteome
Discoverer 1.3 (Thermo Electron, San Jose, CA, USA) against Uniprot Streptococcus suis. fasta database (uniprot streptococcus suis. fasta, 38369 sequences, downloaded at November 4th, 2013) and the decoy database. The following options were used for protein identification. MS/MS tolerance $=0.1 \mathrm{Da}$, Peptide mass tolerance $=20 \mathrm{ppm}$, Enzyme $=$ Trypsin, Missed cleavage $=2$, Fixed modification: Carbamidomethyl (C), iTRAQ 8plex (K), iTRAQ 8plex (N-term), Variable modification:Oxidation (M), $\mathrm{FDR} \leq 0.01$.

\section{Statistical Analysis}

Assays were run in triplicate and the mean \pm standard deviation were calculated. Data were analyzed using the Student's $t$-test.

\section{RESULTS AND DISCUSSION}

\section{Identification and Quantification of Rutin in Syringa oblata Lindl. Aqueous Extract}

The chromatographic characteristics of the compound such as retention time and molecular ions were established under the experimental conditions to determine the rutin in Syringa oblata Lindl. aqueous extract. The typical HPLC chromatograms of sample solution and standard rutin solution were shown in Figure 1. As could be seen, the retention time of the rutin in sample was in good agreement to the authentic compound (17.66 $\mathrm{min})$. In addition, the sample was also analyzed via ESIMS in the negative and positive ion modes (Figure 2). Note that the ESI (-) - MS data (Figure 2A), it demonstrated a molecularion $\left([\mathrm{M}-\mathrm{H}]^{+}\right)$at $\mathrm{m} / \mathrm{z}=609.2$ and a fragment ion at $\mathrm{m} / \mathrm{z}=299.8$. The fragment ion at $\mathrm{m} / \mathrm{z} 299.8$ was produced leaving the rutinoside, suggesting that rutin was converted to quercetin (Regos et al., 2009; Zhao et al., 2013). The sample analysis via ESI-MS in the positive ion mode was shown in Figure 2B, molecular cation was detected mainly in $[\mathrm{M}+$ $\mathrm{Na}]^{+}$form $\left(\mathrm{m} / \mathrm{z}\right.$ 633.2), and minor $[\mathrm{M}+\mathrm{H}]^{+}(\mathrm{m} / \mathrm{z} 611.3)$

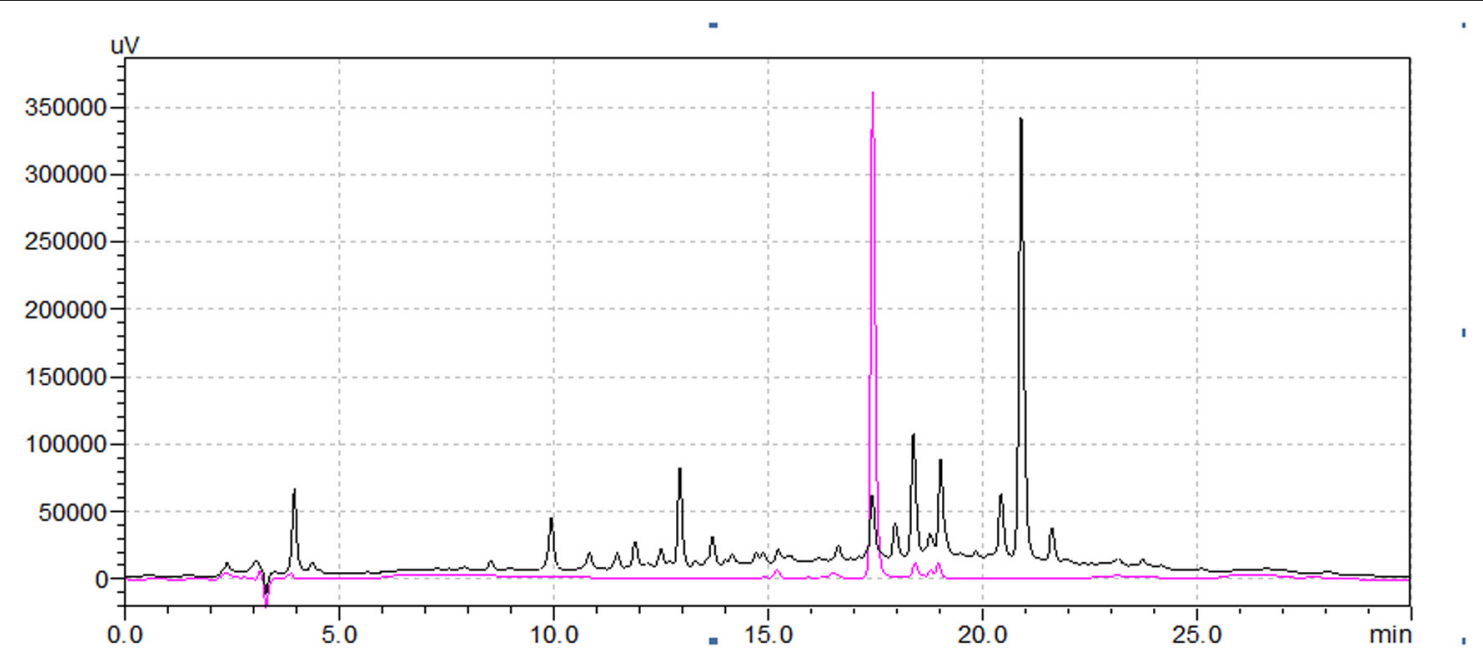

FIGURE 1 | The HPLC chromatograms of the Syringa oblata Lindl. aqueous extract (1) and the rutin standard (2). 
.01: $17.735 \mathrm{~min}$ from Sample 1 (TuneSamplelD) of yang...

A

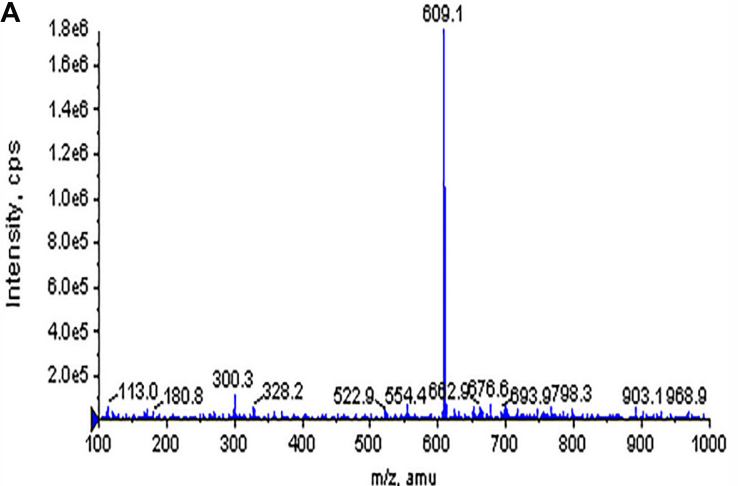

+Q1: 17.534 min from Sample 1 (TuneSampleld) of yan...

Max. 1.3e6 cps.

B

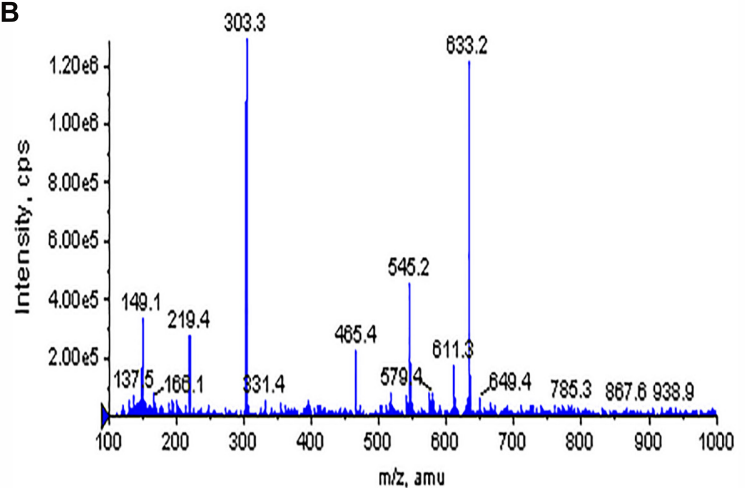

FIGURE 2 | Mass spectra of Syringa oblata Lindl. aqueous extract. (A) MS spectra in negative mode, (B) MS spectra in positive mode.

ion was also detected. The spectrum showed abundant ions at $\mathrm{m} / \mathrm{z} 303.3$ (loss of rutinoside) (Regos et al., 2009; Zhao et al., 2013). Thus, all of these evidences confirmed the existence of rutin in Syringa oblata Lindl. aqueous extract. Quantification of rutin was performed based on the calibration curve which was obtained by plotting peak areas vs. six different concentrations of the standard solutions $(0.0126,0.0252,0.0504,0.1008$, 0.0152 , and $0.2016 \mathrm{mg} / \mathrm{mL}$ ). The calibration curve equation was $y=3 \mathrm{E}+07 \mathrm{x}+93411, R^{2}=0.9991$. As a result, the mean value of rutin in the aqueous extract of Syringa oblata Lindl. was found at $9.9 \pm 0.089 \mathrm{mg} / \mathrm{g}$ dry weight, with a recovery yield of $101.43 \pm 0.99 \%$.

\section{Effect of Syringa oblata Lindl. Aqueous Extract and Rutin against Biofilm Formation In vitro}

Minimal inhibitory concentration of Syringa oblata Lindl. aqueous extract against S. suis ATCC 700794 was determined as $50 \mathrm{mg} / \mathrm{mL}$. Thereafter, we evaluated the action of Syringa oblata Lindl. aqueous extract on biofilm growth in vitro. As reported in Figure 3A, when the culture medium was added with 1/2 MIC, 1/4 MIC, and 1/8 MIC of Syringa oblata Lindl. aqueous extract, the biofilms by $S$. suis were reduced $(p<0.05)$. There was no pronounced effect for 1/16 MIC of Syringa oblata Lindl. aqueous extract on biofilm formation of S. suis $(p>0.05)$. We also evaluated the action of rutin on biofilm growth in vitro. The MIC against $S$. suis was $0.3125 \mathrm{mg} \mathrm{mL}^{-1}$. Rutin at 1/2 MIC and 1/4 MIC caused a significantly higher reduction in the biofilm-forming ability of $S$. suis compared with positive control $(p<0.05)$. However, there was no pronounced effect for $1 / 16$ MIC and $1 / 8$ MIC of rutin on biofilm formation of $S$. suis $(p>0.05)$ (Figure 3B).

Previous studies have shown that sub-MICs of antimicrobial agents can either increase or decrease biofilm formation by bacterial pathogens (Pompilio et al., 2010; Bedran et al., 2014). Our study brought clear evidence that sub-MICs of Syringa oblata Lindl. aqueous extract significantly decreased biofilm formation by $S$. suis. Previous studies have shown that extracts of Syringa plants mainly contain iridoids, lignans, and phenylethanoids that have antitumor, antihypertensive, antioxidant, and anti-inflammatory activities. We further provide evidence that rutin is the effective components of Syringa oblata Lindl. specifically affects $S$. suis biofilm. To the best of our knowledge, it was the first report that sub-MICs of Syringa oblata Lindl. aqueous extract decreased biofilm formed by S. suis.

\section{Direct Observation of Biofilm Formation In vitro by Scanning Electron Microscopy}

Scanning electron microscopy analysis was performed to observe the Syringa oblata Lindl. aqueous extract and rutin sub-MICs-induced $S$. suis biofilm formation. Figures $4 \mathbf{A}, \mathbf{C}$ shows that the surface of the glass slide covered completely by a thick biofilm made of aggregates and microcolonies. However, when the culture medium was added with $1 / 2$ MIC of Syringa oblata Lindl. aqueous extract and rutin, individual pairs of $S$. suis and individual short chains of $S$. suis attached to the glass slide (Figures 4B,D). Scanning electron microscopy analysis revealed that $1 / 2$ MIC of Syringa oblata Lindl. aqueous extract and rutin significantly decreased biofilm formation.

\section{Differentially Expressed Proteins by ITRAQ}

In the present study, iTRAQ technology was used to compare the patterns of protein expression at two different conditions (1/2 MIC of Syringa oblata Lindl. aqueous extract treated and non-treated cells). A ratio of proteins with $>1.5$ or $<0.67(p$ value $<0.05)$ was considered to be differentially expressed. Based on this criterion, twenty-eight differentially expressed proteins were determined, 17 (61\%) of which were up regulated and 11 (39\%) were significantly suppressed (Table 1). The results regarding molecular function were as follows: motor activity $(1,3.6 \%)$, catalytic activity $(17,60.7 \%)$, DNA binding 
A

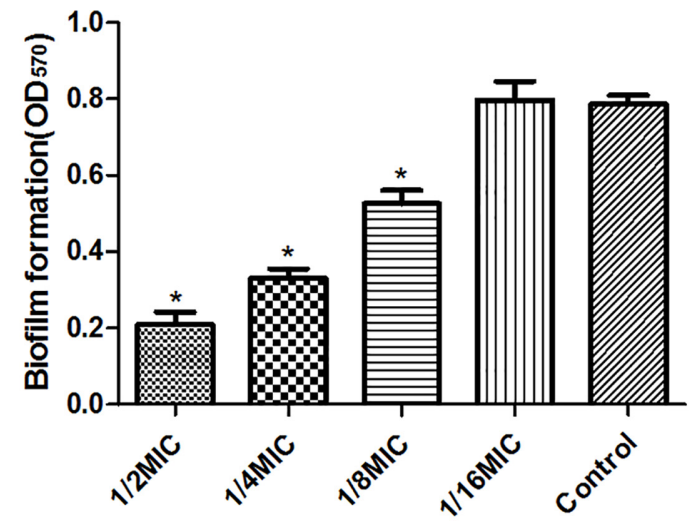

B

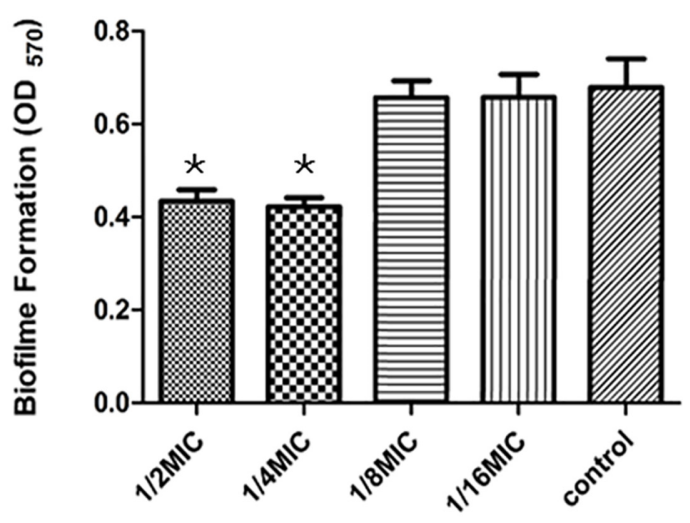

FIGURE 3 | (A) Effect of sub-MICs of Syringa oblata Lindl. aqueous extract on biofilm formation by Streptococcus suis ATCC700794. (B) Effect of sub-MICs of rutin on biofilm formation by S. suis ATCC700794. Data are expressed as means \pm standard deviations. Controls refer to the absence of Syringa oblata Lindl. aqueous extract. Significant decrease $\left({ }^{*} p<0.05\right)$ compared to control bacteria grown in the absence of Syringa oblata Lindl. aqueous extract.
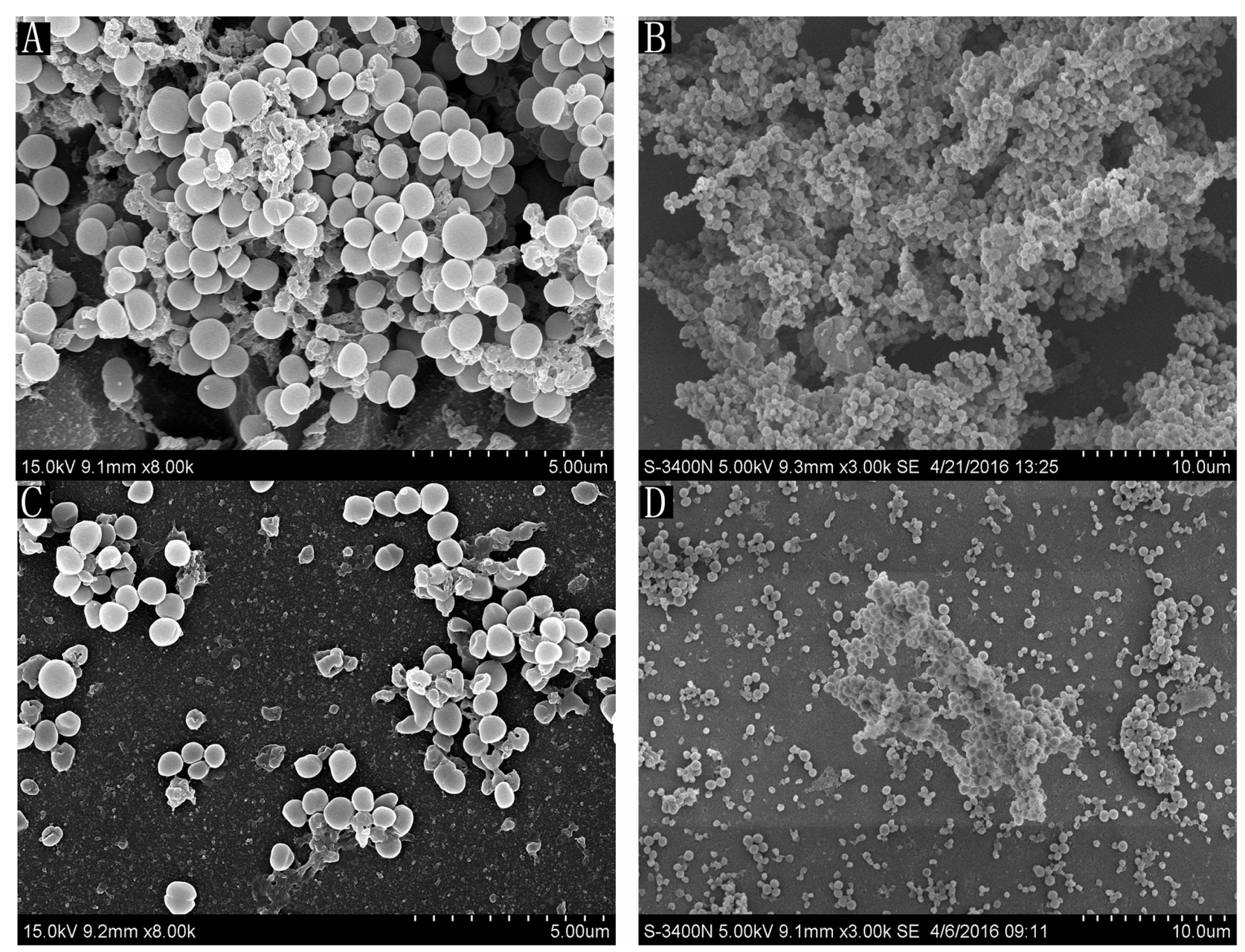

FIGURE 4 | Scanning electron micrographs of S. suis ATCC700794 biofilm following growth in THB supplemented without Syringa oblata Lindl. aqueous extract and rutin (A,C), or with 1/2 MIC of Syringa oblata Lindl. aqueous extract and rutin (B,D). Controls refer to the absence of Syringa oblata Lindl. aqueous extract. 
TABLE 1 | iTRAQ identification of differentially expressed proteins.

\begin{tabular}{|c|c|c|}
\hline Accession & Proteins & Foldchange $^{a}$ \\
\hline \multicolumn{3}{|c|}{ Down-regulated proteins } \\
\hline G7S1J0 & Phosphatase & 0.618 \\
\hline G7RZ18 & Sortase-like protein & 0.644 \\
\hline B9WUV5 & $\begin{array}{l}\text { Transcriptional regulator, DeoR } \\
\text { family }\end{array}$ & 0.527 \\
\hline G7S2M0 & DNA gyrase subunit B & 0.624 \\
\hline D5AGH9 & Antigen-like protein & 0.624 \\
\hline G7SHZ3 & Bacteriophage protein, putative & 0.599 \\
\hline G5KZN4 & DNA polymerase IV & 0.573 \\
\hline M1VJJ3 & CPS6J & 0.585 \\
\hline M1VK55 & CPS28H & 0.568 \\
\hline G5L259 & $\begin{array}{l}\text { NADP-dependent } \\
\text { glyceraldehyde-3-phosphate } \\
\text { dehydrogenase, putative }\end{array}$ & 0.581 \\
\hline G5KZR3 & Glutathione S-transferase & 0.658 \\
\hline \multicolumn{3}{|c|}{ Up-regulated proteins } \\
\hline G5KZ86 & $\begin{array}{l}\text { Phosphatidylserine/ } \\
\text { phosphatidylglycerophosphate/ } \\
\text { cardiolipin synthase-like protein }\end{array}$ & 1.766 \\
\hline \multirow[t]{2}{*}{ J7KIA5 } & $\begin{array}{l}\text { Abortive infection bacteriophage } \\
\text { resistance related protein }\end{array}$ & 1.527 \\
\hline & $\begin{array}{l}\text { Putative competence-damage } \\
\text { inducible protein }\end{array}$ & 1.739 \\
\hline R4NU85 & $\begin{array}{l}\text { Phosphoribosylformylglycinamidine } \\
\text { synthase domain-containing protein }\end{array}$ & 1.964 \\
\hline G7SKQ9 & CPS16F & 2.981 \\
\hline E9NQ13 & Putative uncharacterized protein & 1.671 \\
\hline G5KZE4 & Uncharacterized protein & 1.568 \\
\hline M1VRG0 & Putative uncharacterized protein & 1.654 \\
\hline G7SP92 & Putative uncharacterized protein & 1.570 \\
\hline G5L3A6 & $\begin{array}{l}\text { Plasmid replication protein Rep and } \\
\text { AAA-class ATPase domain protein }\end{array}$ & 2.017 \\
\hline R4NW55 & CPS16V & 2.119 \\
\hline E9NQ29 & Helicase & 1.756 \\
\hline G7S7E3 & Neprilysin (Fragment) & 2.259 \\
\hline BOFYB8 & $\begin{array}{l}\text { ABC superfamily ATP binding } \\
\text { cassette transporter, membrane } \\
\text { protein }\end{array}$ & 2.821 \\
\hline G7SD52 & $\begin{array}{l}\text { Type I site-specific } \\
\text { restriction-modification system, R } \\
\text { (Restriction) subunit and related } \\
\text { helicase }\end{array}$ & 2.538 \\
\hline G7SM99 & Chloramphenicol acetyltransferase & 2.862 \\
\hline C6GT52 & $\begin{array}{l}\text { FAD-dependent pyridine } \\
\text { nucleotide-disulfide oxidoreductase }\end{array}$ & 3.432 \\
\hline G7S7A9 & & \\
\hline
\end{tabular}

a 1/2 MIC of Syringa oblata Lindl. aqueous extract treated vs. non-treated cells.

(5, 17.9\%), metal ion binding (2, 7.1\%), nucleotide binding $(4,14.3 \%)$, protein binding $(1,3.6 \%)$, and unknown molecular function $(10,35.7 \%)$. The results regarding cellular component were as follows: cytoplasm $(4,14.3 \%)$, membrane $(7,25.0 \%)$, cytoskeleton $(1,3.6 \%)$, chromosome $(1,3.6 \%)$, and unknown cellular component $(18,64.3 \%)$. According to the biological process, these proteins were classified into following categories: regulation of biological process $(3,10.7 \%)$, response to stimulus
(3, 10.7\%), metabolic process $(12,42.9 \%)$, cell organization and biogenesis $(1,3.6 \%)$, defense response $(1,3.6 \%)$, cellular homeostasis $(1,3.6 \%)$, transport $(1,3.6 \%)$, and unknown biological process $(14,50.0 \%)$. The majority of the proteins were related to catalytic activity and metabolism. A total of four proteins were classified as hypothetical, and their function is currently unknown. Additionally, three proteins were classified as "probable" and their likely identities were based upon homology to proteins of known function in other related species. For treated cells, various groups of related proteins were shown to be significantly up-regulated or down-regulated. These included those associated with metabolic process. These findings suggested that 1/2 MIC of Syringa oblata Lindl. aqueous extract treated cells and non-treated cells were subjected to different pharmic pressures, which might result in different proteome patterns.

\section{Proteins Involved in Cell Growth and Metabolism}

In the present study, Syringa oblata Lindl. aqueous extract affected metabolism, for example, DNA gyrase subunit B (foldchange: 0.62 ), DNA polymerase IV (fold change: 0.57 ), NADP-dependent glyceraldehyde-3-phosphate dehydrogenase (fold change: 0.58 ), Phosphatase (fold change: 0.62 ). The four proteins were related to cell growth and metabolism. Specifically, bacterial DNA gyrase is the target of many antibiotics (Oblak et al., 2007), such as fluoroquinolones.

\section{Proteins Involved in Capsule Expression}

Streptococcus suis is a Gram-positive bacterium, and it possesses the CPS. Most S. suis strains possess a group of CPS synthesis genes and phenotypically express CPS. Previous studies have also shown that an $S$. suis serotype 2 mutant impaired in capsule expression acquire a biofilm-positive phenotype (Tanabe et al., 2010). Moreover, a hydrophilic capsule may hinder hydrophobic structures or components important for biofilm formation by S. suis (Bonifait et al., 2010). Alternatively, the infection is aggravated by unencapsulation by promoting the ability of bacterial cells to adhere to host cells and form thick biofilms (Benga et al., 2004; Bonifait et al., 2010; Tanabe et al., 2010; Lakkitjaroen et al., 2011). Many different surface molecules, including CPS, may play a fundamental role in pneumococcal biofilm development. Impaired pneumococcal CPS may increase biofilm formation (Qin et al., 2013). In this study, Syringa oblata Lindl. aqueous extract affected the CPS synthesis enzymes, for example, CPS 6J (fold change: 0.59), CPS 28H (fold change: 0.57 ), CPS $16 \mathrm{~F}$ (fold change: 2.98), CPS $16 \mathrm{~V}$ (fold change: 2.12). We speculated that Syringa oblata Lindl. aqueous extract might affect the biosynthesis of the CPS. However, further higher studies are needed to know the detailed molecular mechanism.

In summary, Syringa oblata Lindl. aqueous extract might be used as a potential inhibitor for the control of biofilm formation by S. suis. We found that Syringa oblata Lindl. aqueous extract affected growth, metabolism and the CPS synthesis enzymes. The active ingredient of the Syringa oblata Lindl. aqueous extract was rutin. These data showed a useful starting point for more focused studies to understand what exactly was going on. In future, the 
detailed molecular mechanism may provide further insight in this study.

\section{AUTHOR CONTRIBUTIONS}

JB the design whole experiment. YL directed the completion of the experiment. YY, SW, LG, JC, YR, WD, IM provided help during the experiment.

\section{REFERENCES}

Abbanat, D., Shang, W. C., Amsler, K., Santoro, C., Baum, E., Crespo-Carbone, S., et al. (2014). Evaluation of the in vitro activities of ceftobiprole and comparators in staphylococcal colony or microtitre plate biofilm assays. Int. J. Antimicrob. Agents 43, 32-39. doi: 10.1016/j.ijantimicag.2013.09.013

Bedran, T. B. L., Grignon, L., Spolidorio, D. P., and Grenier, D. (2014). Subinhibitory concentrations of triclosan promote Streptococcus mutans biofilm formation and adherence to oral epithelial cells. PLoS ONE 9:e89059. doi: 10.1371/journal.pone.0089059

Benga, L., Goethe, R., Rohde, M., and Valentin-Weigand, P. (2004). Nonencapsulated strains reveal novel insights in invasion and survival of Streptococcus suis in epithelial cells. Cell Microbiol. 6, 867-881. doi: 10.1111/j. 1462-5822.2004.00409.x

Bonifait, L., Gottschalk, M., and Grenier, D. (2010). Cell surface characteristics of nontypeable isolates of Streptococcus suis. FEMS Microbiol. Lett. 311, 160-166. doi: 10.1111/j.1574-6968.2010.02086.x

Brady, R. A., Leid, J. G., Calhoun, J. H., Costerton, J. W., and Shirtliff, M. E. (2008). Osteomyelitis and the role of biofilms in chronic infection. FEMS Immunol. Med. Microbiol. 52, 13-22. doi: 10.1111/j.1574-695X.2007. 00357.x

Brown, M. R., Allison, D. G., and Gilbert, P. (1988). Resistance of bacterial biofilms to antibiotics: a growth-rate related effect? J. Antimicrob. Chemother. 22, 777-780. doi: 10.1093/jac/22.6.777

Coleman, J. J., Okoli, I., Tegos, G. P., Holson, E. B., Wagner, F. F., Hamblin, M. R., et al. (2010). Characterization of plant-derived saponin natural products against Candida albicans. ACS Chem. Biol. 5, 321-332. doi: 10.1021/cb90 $0243 b$

Ding, X., Yin, B., Qian, L., Zeng, Z. R., Yang, Z. L., Li, H. X., et al. (2011). Screening for novel quorum-sensing inhibitors to interfere with the formation of Pseudomonas aeruginosa biofilm. J. Med. Microbiol. 60, 1827-1834. doi: 10.1099/jmm.0.024166-0

Erlund, I., Kosonen, T., Alfthan, G., Maenpaa, J., Perttunen, K., Kenraali, J., et al. (2000). Pharmacokinetics of quercetin from quercetin aglycone and rutin in healthy volunteers. Eur. J. Clin. Pharmacol. 56, 545-553. doi: 10.1007/ s002280000197

Feng, X. S., Qu, Y., Wu, Z. H., Xu, L., Zhang, D. S., Gao, H. Y., et al. (2009). Two new secoiridoid glucosides from Syringa velutina Kom. Chin. Chem. Lett. 20, 702-705. doi: 10.1016/j.cclet.2009.02.012

Ferrando, M. L., van Baarlen, P., Orru, G., Piga, R., Bongers, R. S., Wels, M., et al. (2014). Carbohydrate availability regulates virulence gene expression in Streptococcus suis. PLoS ONE 9:e89334. doi: 10.1371/journal.pone. 0089334

Goyette-Desjardins, G., Auger, J.-P., Xu, J., Segura, M., and Gottschalk, M. (2014). Streptococcus suis, an important pig pathogen and emerging zoonotic agent-an update on the worldwide distribution based on serotyping and sequence typing. Emerg. Microbes Infect. 3:e45. doi: 10.1038/emi.2014.45

Koh, C. L., Sam, C. K., Yin, W. F., Tan, L. Y., Krishnan, T., Chong, Y. M., et al. (2013). Plant-derived natural products as sources of antiquorum sensing compounds. Sensors 13, 6217-6228. doi: 10.3390/s130 506217

Lakkitjaroen, N., Takamatsu, D., Okura, M., Sato, M., Osaki, M., and Sekizaki, T. (2011). Loss of capsule among Streptococcus suis isolates from porcine endocarditis and its biological significance. J. Med. Microbiol. 60, 1669-1676. doi: 10.1099/jmm.0.034686-0

\section{ACKNOWLEDGMENTS}

This work was supported by the National Natural Science Foundation of China (No. 820055), Scientific research project of Heilongjiang province education department (No. 12531037), Postdoctoral fellowship in Heilongjiang province (LBH-Z1) and Scientific research project of Heilongjiang province education department (No. 12531044). Thank to Shanghai Applied Protein Technology, Co. Ltd for the help of iTRAQ.

Lee, H. W., Koh, Y. M., Kim, J., Lee, J. C., Lee, Y. C., Seol, S. Y., et al. (2008). Capacity of multidrug-resistant clinical isolates of Acinetobacter baumannii to form biofilm and adhere to epithelial cell surfaces. Clin. Microbiol. Infect. 14, 49-54. doi: 10.1111/j.1469-0691.2007.01842.x

Liu, Z. J., Zheng, H., Gottschalk, M., Bai, X. M., Lan, R. T., Ji, S. B., et al. (2013). Development of multiplex PCR assays for the identification of the 33 serotypes of Streptococcus suis. PLoS ONE 8:e72070. doi: 10.1371/journal.pone. 0072070

Middleton, E. Jr., Kandaswami, C., and Theoharides, T. C. (2000). The effects of plant flavonoids on mammalian cells: implications for inflammation, heart disease, and cancer. Pharmacol. Rev. 52, 673-751.

Oblak, M., Kotnik, M., and Solmajer, T. (2007). Discovery and development of ATPase inhibitors of DNA gyrase as antibacterial agents. Curr. Med. Chem. 14, 2033-2047. doi: 10.2174/092986707781368414

Park, H. J., Lee, M. S., Lee, K. T., Sohn, I. C., Han, Y. N., and Miyamoto, K. (1999). Studies on constituents with cytotoxic activity from the stem bark of Syringa velutina. Chem. Pharm. Bull. 47, 1029-1031. doi: 10.1248/cpb. 47.1029

Pompilio, A., Catavitello, C., Picciani, C., Confalone, P., Piccolomini, R., Savini, V., et al. (2010). Subinhibitory concentrations of moxifloxacin decrease adhesion and biofilm formation of Stenotrophomonas maltophilia from cystic fibrosis. J. Med. Microbiol. 59, 76-81. doi: 10.1099/Jmm.0.011981-0

Qin, L., Kida, Y., Imamura, Y., Kuwano, K., and Watanabe, H. (2013). Impaired capsular polysaccharide is relevant to enhanced biofilm formation and lower virulence in Streptococcus pneumoniae. J. Infect. Chemother. 19, 261-271. doi: 10.1007/s10156-012-0495-3

Rao, R. S., Karthika, R. U., Singh, S. P., Shashikala, P., Kanungo, R., Jayachandran, S., et al. (2008). Correlation between biofilm production and multiple drug resistance in imipenem resistant clinical isolates of Acinetobacter baumannii. Indian J. Med. Microbiol. 26, 333-337. doi: 10.4103/0255-0857. 43566

Regos, I., Urbanella, A., and Treutter, D. (2009). Identification and quantification of phenolic compounds from the forage legume sainfoin (Onobrychis viciifolia). J. Agric. Food Chem. 57, 5843-5852. doi: 10.1021/jf900625r

Smith, H. E., Damman, M., van der Velde, J., Wagenaar, F., Wisselink, H. J., Stockhofe-Zurwieden, N., et al. (1999). Identification and characterization of the cps locus of Streptococcus suis serotype 2: the capsule protects against phagocytosis and is an important virulence factor. Infect. Immun. 67, 17501756.

Tanabe, S. I., Bonifait, L., Fittipaldi, N., Grignon, L., Gottschalk, M., and Grenier, D. (2010). Pleiotropic effects of polysaccharide capsule loss on selected biological properties of Streptococcus suis. Can. J. Vet. Res. 74, 65-70.

Taylor, P. W. (2013). Alternative natural sources for a new generation of antibacterial agents. Int. J. Antimicrob. Agents 42, 195-201. doi: 10.1016/j. ijantimicag.2013.05.004

Wang, K. C., Fan, W. X., Cai, L. J., Huang, B. X., and Lu, C. P. (2011). Genetic analysis of the capsular polysaccharide synthesis locus in 15 Streptococcus suis serotypes. FEMS Microbiol. Lett. 324, 117-124. doi: 10.1111/j.1574-6968.2011. 02394.x

Wiegand, I., Hilpert, K., and Hancock, R. E. W. (2008). Agar and broth dilution methods to determine the minimal inhibitory concentration (MIC) of antimicrobial substances. Nat. Protoc. 3, 163-175. doi: 10.1038/nprot.2007.521

Wisniewski, J. R., Zougman, A., Nagaraj, N., and Mann, M. (2009). Universal sample preparation method for proteome analysis. Nat. Methods 6, 359-362. doi: 10.1038/nmeth.1322 
Yang, Y.-B., Wang, S., Wang, C., Huang, Q.-Y., Bai, J.-W., Chen, J.-Q., et al. (2015). Emodin affects biofilm formation and expression of virulence factors in Streptococcus suis ATCC700794. Arch. Microbiol. 197, 1173-1180. doi: 10.1007/ s00203-015-1158-4

Zhao, Y. L., Zhou, Y. H., Chen, J. Q., Huang, Q. Y., Han, Q., Liu, B., et al. (2015). Quantitative proteomic analysis of sub-MIC erythromycin inhibiting biofilm formation of S. suis in vitro. J. Proteomics 116, 1-14. doi: 10.1016/j.jprot.2014. 12.019

Zhao, Z. Y., Dong, L. L., Lin, F., and Wu, Y. L. (2013). Simultaneous characterization and quantification of flavonoids in Euonymus alatus (Thunb.) Siebold from different origins by HPLC-PAD-MS. Arabian J. Chem. 6, 205-209. doi: 10.1016/j.arabjc.2010.10.003

Zhu, J., Beaber, J. W., More, M. I., Fuqua, C., Eberhard, A., and Winans, S. C. (1998). Analogs of the autoinducer 3-oxooctanoyl-homoserine lactone strongly inhibit activity of the TraR protein of Agrobacterium tumefaciens. J. Bacteriol. $180,5398-5405$.

Conflict of Interest Statement: The authors declare that the research was conducted in the absence of any commercial or financial relationships that could be construed as a potential conflict of interest.

Copyright (c) 2017 Bai, Yang, Wang, Gao, Chen, Ren, Ding, Muhammad and Li. This is an open-access article distributed under the terms of the Creative Commons Attribution License (CC BY). The use, distribution or reproduction in other forums is permitted, provided the original author(s) or licensor are credited and that the original publication in this journal is cited, in accordance with accepted academic practice. No use, distribution or reproduction is permitted which does not comply with these terms. 